\title{
DNA-PK Deficiency in Alzheimer's Disease
}

\author{
Jyotshna Kanungo*
}

Division of Neurotoxicology, National Center for Toxicological Research, US Food and Drug Administration, 3900 NCTR Road, Jefferson, AR 72079, USA

\section{Article Info}

\section{Article Notes}

Received: April 25, 2016

Accepted: June 07, 2016

${ }^{*}$ Correspondence:

Dr. Jyotshna Kanungo

Division of Neurotoxicology

National Center for Toxicological Research

U.S. Food and Drug Administration

3900 NCTR Road,

Jefferson, AR 72079 USA

Telephone: 870-543-7591

Fax: 870-543-7143

Email: jyotshnabala.kanungo@fda.hhs.gov

(c) 2016 Kanungo J. This article is distributed under the terms of the Creative Commons Attribution 4.0 International License

\section{Keywords}

DNA-PK

$\mathrm{Ku}$

DNA Break

NHEJ

Alzheimer's Disease

\section{ABSTRACT}

Alzheimer's disease (AD) is characterized by neuronal death with an accumulation of intra-cellular neurofibrillary tangles (NFT) and extracellular amyloid plaques. Reduced DNA repair ability has been reported in AD brains. In neurons, the predominant mechanism to repair double-strand DNA breaks (DSB) is non-homologous end joining (NHEJ) that requires DNA-dependent protein kinase (DNA-PK) activity. DNA-PK is a holoenzyme comprising the p460 KD DNA-PK catalytic subunit (DNA-PKcs) and its activator Ku, a heterodimer of p86 (Ku80) and p70 (Ku70) subunits. Upon binding to double-stranded DNA ends, Ku recruits DNA-PKcs to process NHEJ. In AD brains, reduced NHEJ activity as well as DNA-PKcs and Ku protein levels have been shown. Normal aging brains also show a reduction in both DNA-PKcs and Ku levels questioning a direct link between NHEJ ability and $A D$, and suggesting additional players/ events in AD pathogenesis. Deficiency of Ku80, a somatostatin receptor, can disrupt somatostatin signaling thus inducing amyloid beta $(A \beta)$ generation, which in turn can potentiate DNA-PKcs degradation and consequently loss of NHEJ activity, an additional step negatively affecting DSB repair. Trigger of these two different pathways culminating in genome instability may differentiate the outcomes between $A D$ and normal aging.

Alzheimer's disease (AD) is a CNS neurodegenerative disease, characterized by specific neuronal death with accumulated neurofibrillary tangles (NFT) and extracellular amyloid beta (A $\beta$ ) deposits ${ }^{1}$. A $\beta$ directly injures neocortical and limbic system neurons $\mathrm{s}^{2}$. It also indirectly activates the microglia that release proinflammatory cytokines and reactive oxygen species (ROS), both events being neurotoxic ${ }^{3,4}$. Other factors linked to the development of $\mathrm{AD}$ include apolipoprotein $\mathrm{E}$ genotype ${ }^{5}$; hyperphosphorylation of cytoskeletal proteins (neurofilaments and Tau) ${ }^{6}$, and $A \beta$ metabolism ${ }^{7}$. As diverse as the pathological and biochemical presentations of $\mathrm{AD}$ are $^{8}$, no single factor has been confirmed as the sole cause of this complex disease ${ }^{9-12}$. Studies have shown a link between oxidative stress (e.g., ROS) and AD pathogenesis ${ }^{11,13,14}$. Since oxidative stress can cause DNA lesions, changes in the levels and activity of DNA-repair proteins have garnered special interest of study of AD patients or patients with mild cognitive impairment ${ }^{15,16}$.

Cellular damage by oxidative stress caused by the generation of ROS has been implicated in pathophysiology of AD as well as normal aging and elevated levels of oxidative damage in DNA, both nuclear and mitochondrial, have been observed in AD brains ${ }^{17}$. As DNA damage accumulates and DNA repair process lags or goes awry, a potentially adverse scenario can set in contributing to $\mathrm{AD}^{18,19}$. 
Some human hereditary genetic defects in the DNA repair system also manifest in early onset of developmental and progressive neurodegeneration ${ }^{20,21}$. Cells use several types of DNA repair systems such as base excision repair (BER), nucleotide excision repair (NER), single strand break repair (SSBR), and double strand break repair (DSBR). Of all these various DNA damages, double strand break (DSB) happens to be the most lethal. There are two major DSB repair pathways in the eukaryotes; non-homologous end joining (NHEJ) and homologous recombination (HR). NHEJ, the predominant pathway for DSBR in higher order organisms, functions throughout the cell cycle ${ }^{22-24}$, whereas HR functions are confined to the S and G2 stages of the cell cycle $^{25}$. DNA-PK plays an essential role in accessing the DNA ends during $\mathrm{NHEJ}^{26,27}$.

As a response to DNA damage, expression and activity of many kinases including members of the PI3 kinase family are altered ${ }^{28}$. One of these kinases, the DNA-dependent protein kinase (DNA-PK) preferentially phosphorylates the serines $(\mathrm{S})$ and threonines $(\mathrm{T})$ of its targets although it can also phosphorylate other S-T/hydrophobic residues ${ }^{29}$. DNA-PK holoenzyme consists of a catalytic subunit (DNA-PK ${ }_{c s}$ ), p460 and a regulatory subunit (Ku). The $\mathrm{Ku}$ protein is a heterodimer composed of $70 \mathrm{kD}(\mathrm{Ku} 70)$ and $80 \mathrm{kD}$ (Ku80) subunits; and possesses the ability to bind to DNA ends ${ }^{30,31}$. DNA-PK is conserved across species ${ }^{32,33}$ and participates in transcription, DNA recombination and repair ${ }^{34-38}$. In the absence of DNA-PK ${ }_{c s}, \mathrm{Ku}$ binds DNA ends in a sequence-independent manner ${ }^{39}$, however, $\mathrm{Ku}$ is required for targeting DNA-PK $\mathrm{cs}_{\mathrm{cs}}$ to damaged DNA ends in physiologic conditions in vitro and in living cells ${ }^{40}$ DSB can activate DNA-PK both in trans (occurs via kinase autophosphrylation) or cis (occurs via specific DNA strand orientation and sequence bias) modes ${ }^{41-43}$.

Post-mitotic neurons are mature, do not proliferate ${ }^{44,45}$ and are also one of the most metabolically and transcriptionally active cells (review ${ }^{46}$ ). Therefore, these neurons are more susceptible to suffer from risks involving DNA damage. NHEJ, unlike HR, is error-prone since it acts at the DNA break points and the repair process can cause loss of one or more nucleotides. However, since most of the higher eukaryote genome is non-coding, errors occurred during DSBR by NHEJ rarely translate into any deleterious effects. Unfortunately, as people age, accumulation of these non-obvious errors eventually can lead to genome instability, thereby causing cellular death or dysfunction. For example, $10 \%$ of p53 mutations in human cancers could be attributed to deletions arising from NHEJ sites ${ }^{47}$. NHEJ being the predominant form of DSBR pathway in postmitotic neurons ${ }^{48}$, mouse neurons deficient in components of NHEJ, such as XLF, DNA Ligase IV, XRCC4, Ku70 and Ku80 (Figure 1), undergo excessive apoptosis ${ }^{49,50}$. Mice with defective NHEJ show accelerated aging ${ }^{51,52}$. Loss of NHEJ activity in the developing brain causes prenatal lethality and can lead to neurodegenerative diseases in adults ${ }^{49,53,54}$.

Terminally differentiated post-mitotic neurons triggered to re-enter cell cycle following stimuli associated with DNA damage and oxidative stress undergo apoptosis ${ }^{55,56}$. Neuronal DNA damage is linked to neurons re-entering cell cycle ${ }^{56,57}$. To this end, DNA replication may be a consequence of cell cycle re-entry preceding neurodegeneration in $\mathrm{AD}$ brains ${ }^{58}$. Moreover, reactive oxygen/nitrogen species reportedly cause deregulated and inefficient DNA replication known as 'replication stress' ${ }^{59}$. It is possible that "replication stress" in AD pathogenesis can lead to genomic instability potentially resulting in $\mathrm{A} \beta$ accumulation and deregulated cell cycles $^{60}$. Adding to this scenario, existence of defective DNA repair systems in post-mitotic neurons would lead to accumulation of further DNA damages and genomic instabilities ${ }^{61,62}$ (Figure $1)$. It has been suggested that accumulated single-stranded DNA (ssDNA) at replication forks may give rise to aberrant DNA structures resulting in DSBs that activate DNA-PK ${ }^{63}$. With this scenario, in AD, reduced DNA-PK as such would further enhance DSB accumulation. Intracellular increase in DNA content observed in $\mathrm{AD}$ brains ${ }^{58,64}$ may also result from these combined events. Indeed, it has been reported that DNA-PK ${ }_{c s}$ mutant cells under stress fail to arrest replication ${ }^{65}$. Thus, neurons deficient in DNA-PK activity could uninterruptedly undergo replication stress ending with genome instability (Figure 1).

DNA-PK plays a critical role, first, by sensing DNA damage and then, inducing signaling pathways including programmed cell death ${ }^{51}$. Ku $80^{-\%}$ mice are defective in NHEJ, telomere maintenance and show premature aging ${ }^{52,66}$. Ku80 and DNA-PK $\mathrm{cs}$ protein levels as well as Ku80's DNA-binding ability are reduced following severe ischemic injury leading to neuronal death in rabbit ${ }^{67}$. Furthermore, although not significantly different from the age-matched controls, KuDNA binding is reduced in extracts of post-mortem AD mid-frontal cortex that may be linked to reduced levels of $\mathrm{Ku}$ and DNA-PK proteins $^{68}$. Reduced NHEJ activity in extracts of the cortices of AD brains compared to the normal subjects and significantly lower levels of DNA-PK in the $\mathrm{AD}$ brain extracts have also been reported ${ }^{69}$. Since DNA-PK is a critical player in cell survival/death and gene transcription, it is tempting to directly link reduced levels of DNA-PK subunits to less proficient NHEJ in AD brains and neurodegeneration. It is likely that DNA damage (e.g., induced by ROS) in neurons that are already challenged with reduced NHEJ activity, may trigger them to re-enter cell cycle albeit unsuccessfully, resulting in accumulation of excessive genomic damage leading to neuronal death. Therefore, reduced levels of DNA-PK $\mathrm{P}_{c s}$ and $\mathrm{Ku} 80 / \mathrm{Ku} 70$ subunits in post-mortem AD brains may be an important upstream event that predisposes the neurons to AD. 
In NGF-differentiated PC12 cells, sub-lethal levels of aggregated $A \beta^{25-35}$ have been shown to inhibit DNA-PK activity as does hydrogen peroxide ${ }^{70}$. One of its potential mechanisms may be $A \beta$-induced ROS-mediated DNA-PK degradation via carbonylation, an irreversible oxidative

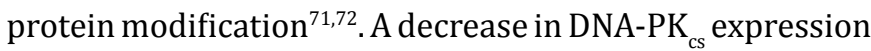
in neurons and astrocytes of $\mathrm{AD}$ brains $^{73}$, although not significant compared to age-matched controls, has been reported ${ }^{74}$. Whether $A \beta$-induced attenuation of DNA-PK activity and reduced NHEJ activity (Figure 1) leading to neurotoxicity is linked to the development of $\mathrm{AD}$ awaits careful scrutiny.

Ku80 has been shown to be a specific receptor for somatostatin $^{75}$ and can regulate DNA-PK activity through somatostatin signaling pathways ${ }^{76}$. Somatostatin modulates both motor activity and cognition ${ }^{77}$. Somatostatinergic neurons exist in the CNS including the cerebral cortex, hippocampus, hypothalamus, and spinal $\operatorname{cord}^{78}$. Along with various other neuropeptides, somatostatin levels are significantly reduced in $\mathrm{AD}$ brains ${ }^{79}$ and cerebrospinal fluid $^{80}$. Somatostatin receptors are also reduced in the cortical areas of the AD brain ${ }^{81}$. Loss of somatostatinergic neurons along with reduction in somatostatin transcripts in a transgenic mouse model of $\mathrm{AD}$, and somatostatin deficiency potentially triggering $A \beta$ generation have been reported ${ }^{82}$. It is possible that Ku80 deficiency can negatively affect somatostatin signaling leading to $A \beta$ generation, thereby contributing to $\mathrm{AD}$ pathogenesis, a process independent of the involvement of DSB (Figure 1).

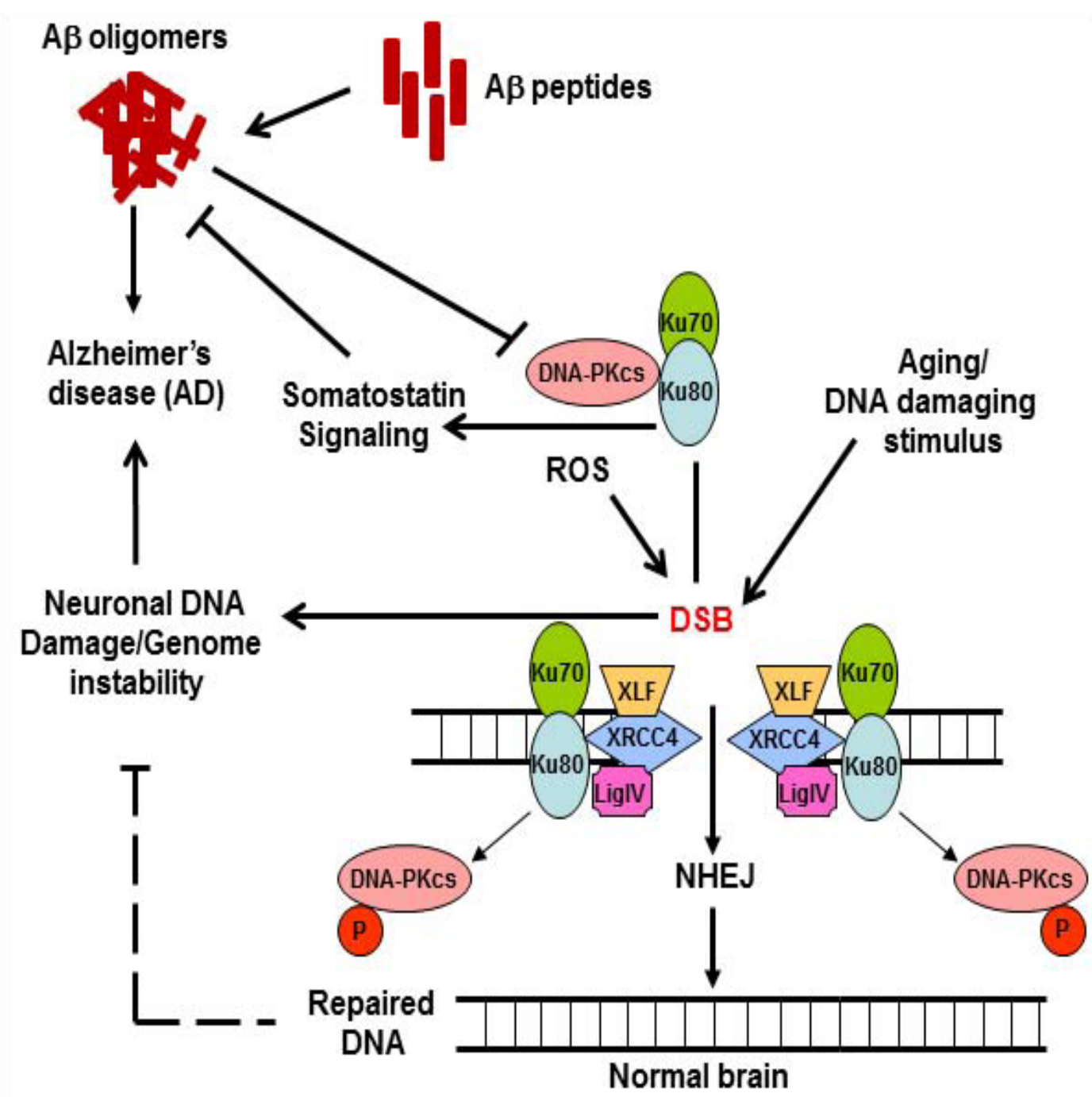

Figure 1: Schematic presentation of a potential link of DSB, DNA-PK and A $\beta$ in AD brains. Upon induction of DSB either by normal aging/ ROS or other DNA damaging agents, Ku80/Ku70 and DNA-PKcs are rapidly recruited to DNA ends, and DNA repair occurs as it would in normal cases. However, in $A D$ brains, in addition to formation of $A \beta$ oligomers from $A \beta$ peptides, sustained DSB in the genome would cause genome instability leading to the loss of normal neuronal activity. Additionally, with depleted Ku80, a somatostatin receptor, disruption of somatostatin signaling could potentially induce $A \beta$ generation thus accelerating $A D$ pathology.

DSB: DNA double strand break; DNA-PK: DNA-dependent protein kinase; ROS: Reactive oxygen species; A $\beta$ Amyloid beta 
DNA-PK ${ }_{c s^{\prime}}$ Ku80 and Ku70 are exceptionally abundant proteins in human cells ${ }^{83}$. Reduced level of DNA-PK $\mathrm{cs}_{\text {in }}$ $\mathrm{AD}$ brains has been attributed to $\mathrm{A} \beta$-induced proteasomemediated degradation of DNA-PK ${ }_{\mathrm{cs}}{ }^{71,72}$. Whether disruption of the somatostatin signaling due to Ku80 deficiency inducing $\mathrm{A} \beta$ generation precedes $\mathrm{DNA}-\mathrm{PK}_{\mathrm{cs}}$ degradation is not known. If true, it would highlight Ku80 as a dual player in $\mathrm{AD}$ pathogenesis; when deficient, by indirectly promoting $\mathrm{A} \beta$ generation and directly causing NHEJ deficiency.

\section{Abbreviations}

AD: Alzheimer's disease; ATM: Ataxia telangiectasia mutated protein; BER: base excision repair; DNA-PK: DNAdependent protein kinase; DSB: double strand breaks; DSBR: Double strand break repair; HR: Homologous recombination; NER: Nucleotide excision repair; NGF: Nerve growth factor; Lig IV: Ligase IV; NHEJ: Nonhomologous end-joining; NFT: Neurofibrillary tangle; SSBR: Single strand break repair; XLF: XRCC4-like factor; XRCC4: X-ray repair cross-complementing protein 4

\section{Acknowledgements}

This document has been reviewed in accordance with United States Food and Drug Administration (FDA) policy and approved for publication. Approval does not signify that the contents necessarily reflect the position or opinions of the FDA nor does mention of trade names or commercial products constitute endorsement or recommendation for use. The findings and conclusions in this report are those of the author and do not necessarily represent the views of the FDA.

\section{References}

1. Smith MA, Perry G. The pathogenesis of Alzheimer disease: an alternative to the amyloid hypothesis. J Neuropathol Exp Neurol. 1997;56(2):217.

2. Mucke L, Selkoe DJ. Neurotoxicity of amyloid $\beta$-protein: synaptic and network dysfunction. Cold Spring Harb Perspect Med. 2012;2(7):a006338.

3. Czirr E, Wyss-coray T. The immunology of neurodegeneration. J Clin Invest. 2012;122(4):1156-63.

4. Wyss-coray T, Rogers J. Inflammation in Alzheimer disease-a brief review of the basic science and clinical literature. Cold Spring Harb Perspect Med. 2012;2(1):a006346.

5. Corder EH, Saunders AM, Strittmatter WJ, et al. Gene dose of apolipoprotein E type 4 allele and the risk of Alzheimer's disease in late onset families. Science. 1993;261(5123):921-3.

6. Trojanowski JQ, Schmidt ML, Shin RW, Bramblett GT, Rao D, Lee VM. Altered tau and neurofilament proteins in neuro-degenerative diseases: diagnostic implications for Alzheimer's disease and Lewy body dementias. Brain Pathol. 1993;3(1):45-54.

7. Selkoe DJ.Alzheimer's disease: genotypes, phenotypes, and treatments. Science. 1997;275(5300):630-1.

8. Scheltens P, Blennow K, Breteler MM, de Strooper B, Frisoni GB, Salloway S et al. Alzheimer's disease. Lancet. 2016; doi: 10.1016/ S0140-6736(15)01124-1
9. Barnes J, Dickerson BC, Frost C, Jiskoot LC, Wolk D, Van der flier WM. Alzheimer's disease first symptoms are age dependent: Evidence from the NACC dataset. Alzheimers Dement. 2015;11(11):1349-57.

10. Crutch SJ, Schott JM, Rabinovici GD, Boeve BF, Cappa SF, Dickerson BC, et al. Shining a light on posterior cortical atrophy. Alzheimers Dement. 2013; 9:463-5.

11. Murray IV, Proza JF, Sohrabji F, Lawler JM. Vascular and metabolic dysfunction in Alzheimer's disease: a review. Exp Biol Med (Maywood). 2011;236(7):772-82.

12.Van der flier WM, Pijnenburg YA, Fox NC, Scheltens P. Early-onset versus late-onset Alzheimer's disease: the case of the missing APOE $\varepsilon 4$ allele. Lancet Neurol. 2011;10(3):280-8.

13.Aldred S, Bennett S, Mecocci P. Increased low-density lipoprotein oxidation, but not total plasma protein oxidation, in Alzheimer's disease. Clin Biochem. 2010; 43:267-71.

14. Bennett S, Grant MM, Aldred S. Oxidative stress in vascular dementia and Alzheimer's disease: a common pathology. J Alzheimers Dis. 2009;17(2):245-57.

15. Bennett G, Papamichos-chronakis M, Peterson CL. DNA repair choice defines a common pathway for recruitment of chromatin regulators. Nat Commun. 2013;4:2084.

16. Bucholtz N, Demuth I. DNA-repair in mild cognitive impairment and Alzheimer's disease. DNA Repair (Amst). 2013;12(10):811-6.

17.Wang J, Xiong S, Xie C, Markesbery WR, Lovell MA. Increased oxidative damage in nuclear and mitochondrial DNA in Alzheimer's disease. J Neurochem. 2005;93(4):953-62.

18. Adamec E, Vonsattel JP, Nixon RA. DNA strand breaks in Alzheimer's disease. Brain Res. 1999;849(1-2):67-77.

19. Love S, Barber R, Wilcock GK. Apoptosis and expression of DNA repair proteins in ischaemic brain injury in man. Neuroreport. 1998;9(6):955-9.

20.Gueven N, Chen P, Nakamura J, et al. A subgroup of spinocerebellar ataxias defective in DNA damage responses. Neuroscience. 2007;145(4):1418-25.

21. Lee Y, Mckinnon PJ. Responding to DNA double strand breaks in the nervous system. Neuroscience. 2007;145(4):1365-74.

22. Critchlow SE, Jackson SP. DNA end-joining: from yeast to man. Trends Biochem Sci. 1998;23(10):394-8.

23.Lieber MR. The biochemistry and biological significance of nonhomologous DNA end joining: an essential repair process in multicellular eukaryotes. Genes Cells. 1999;4(2):77-85.

24. Pastink A, Eeken JC, Lohman PH. Genomic integrity and the repair of double-strand DNA breaks. Mutat Res. 2001;480-481:37-50.

25. Rothkamm K, Krüger I, Thompson LH, Löbrich M. Pathways of DNA double-strand break repair during the mammalian cell cycle. Mol Cell Biol. 2003;23(16):5706-15

26. Kienker LJ, Shin EK, Meek K. Both V(D)J recombination and radioresistance require DNA-PK kinase activity, though minimal levels suffice for V(D)J recombination. Nucleic Acids Res. 2000;28(14):2752 61

27. Oksenych V, Kumar V, Liu X, et al. Functional redundancy between the XLF and DNA-PKcs DNA repair factors in V(D)J recombination and nonhomologous DNA end joining. Proc Natl Acad Sci USA. 2013;110(6):2234-9.

28. Bensimon A, Aebersold R, Shiloh Y. Beyond ATM: the protein kinase landscape of the DNA damage response. FEBS Lett. 2011;585(11):162539

29. Lees-Miller SP, Meek K. Repair of DNA double strand breaks by nonhomologous end joining. Biochimie. 2003; 85:1161-73. 
30. De vries E, Van driel W, Bergsma WG, Arnberg AC, Van der vliet PC. HeLa nuclear protein recognizing DNA termini and translocating on DNA forming a regular DNA-multimeric protein complex. J Mol Biol. 1989;208(1):65-78.

31. Mimori , Hardin JA. Mechanism of interaction between Ku protein and DNA. J Biol Chem. 1986; 261:10375-9.

32. Kanungo J. Prolonged incubation in seawater induces a DNA-dependent protein phosphorylation activity in Arbacia punctulata eggs. Biochem Biophys Res Commun. 2002;294(3):667-71.

33. Kanungo J. DNase I-resistant DNA-dependent protein kinase activity in Xenopus oocytes. Mol Cell Biochem. 2008;309(1-2):33-40.

34. Carter T, Vancurová I, Sun I, Lou W, Deleon S. A DNA-activated protein kinase from HeLa cell nuclei. Mol Cell Biol. 1990;10(12):6460-71.

35. Jackson SP, Macdonald JJ, Lees-miller S, Tjian R. GC box binding induces phosphorylation of Sp1 by a DNA-dependent protein kinase. Cell. 1990;63(1):155-65.

36. Satoh MS, Lindahl T. Role of poly(ADP-ribose) formation in DNA repair. Nature. 1992;356(6367):356-8.

37. Liang F, Romanienko PJ, Weaver DT, Jeggo PA, Jasin M. Chromosomal double-strand break repair in Ku80-deficient cells. Proc Natl Acad Sci USA. 1996;93(17):8929-33.

38. Kanungo J, Wang HY, Malbon CC. Ku80 is required but not sufficient for Galpha13-mediated endodermal differentiation in P19 embryonic carcinoma cells. Biochem Biophys Res Commun. 2004; 323:293-8.

39. Walker JR, Corpina RA, Goldberg J. Structure of the Ku heterodimer bound to DNA and its implications for double-strand break repair Nature. 2001;412(6847):607-14

40. Drouet J, Delteil C, Lefrançois J, Concannon P, Salles B, Calsou P. DNAdependent protein kinase and XRCC4-DNA ligase IV mobilization in the cell in response to DNA double strand breaks. J Biol Chem. 2005;280(8):7060-9.

41. Dobbs TA, Tainer JA, Lees-miller SP. A structural model for regulation of NHEJ by DNA-PKcs autophosphorylation. DNA Repair (Amst) 2010;9(12):1307-14.

42. Nagasawa H, Little JB, Lin YF, et al. Differential role of DNA-PKcs phosphorylations and kinase activity in radiosensitivity and chromosomal instability. Radiat Res. 2011;175(1):83-9.

43. Reddy YV, Ding Q, Lees-miller SP, Meek K, Ramsden DA. Nonhomologous end joining requires that the DNA-PK complex undergo an autophosphorylation-dependent rearrangement at DNA ends. J Biol Chem. 2004;279(38):39408-13.

44. Korr H. Proliferation of different cell types in the brain of senile mice autoradiographic studies with 3H- and 14C-thymidine. Exp Brain Res. 1982;Suppl 5:51-7.

45. Ridet JL, Malhotra SK, Privat A, Gage FH. Reactive astrocytes: cellular and molecular cues to biological function. Trends Neurosci. 1997;20(12):570-7.

46. Rao KS . DNA repair in aging rat neurons. Neuroscience. 2007; 145:1330-40

47. Greenblatt MS, Grollman AP, Harris CC. Deletions and insertions in the p53 tumor suppressor gene in human cancers: confirmation of the DNA polymerase slippage/misalignment model. Cancer Res. 1996;56(9):2130-6.

48. Rass U, Ahel I, West SC. Defective DNA repair and neurodegenerative disease. Cell. 2007;130(6):991-1004. 10.1016/j.cell.2007.08.043

49. Brooks PJ. DNA repair in neural cells: basic science and clinical implications. Mutat Res. 2002;509(1-2):93-108.

50. Sekiguchi JM, Gao Y, Gu Y, et al. Nonhomologous end-joining proteins are required for $V(D) J$ recombination, normal growth, and neurogenesis. Cold Spring Harb Symp Quant Biol. 1999;64:169-81.
51.Smith GC, Jackson SP.The DNA-dependent protein kinase. Genes Dev. 1999; 13:916-34

52.Vogel H, Lim DS, Karsenty G, Finegold M, Hasty P. Deletion of Ku86 causes early onset of senescence in mice. Proc Natl Acad Sci USA. 1999;96(19):10770-5.

53. Mckinnon PJ, Caldecott KW. DNA strand break repair and human genetic disease. Annu Rev Genomics Hum Genet. 2007;8:37-55.

54.Yang Y, Herrup K. Loss of neuronal cell cycle control in ataxiatelangiectasia: a unified disease mechanism. J Neurosci. 2005;25(10):2522-9.

55.Krantic S, Mechawar N, Reix S, Quirion R. Molecular basis of programmed cell death involved in neurodegeneration. Trends Neurosci. 2005;28(12):670-6

56. Kruman II, Wersto RP, Cardozo-pelaez F, et al. Cell cycle activation linked to neuronal cell death initiated by DNA damage. Neuron. 2004;41(4):549-61.

57. McMurray CT. To die or not to die: DNA repair in neurons. Mutat Res. $2005 ; 577: 260-74$.

58. Yang Y, Geldmacher DS, Herrup K. DNA replication precedes neuronal cell death in Alzheimer's disease. J Neurosci. 2001;21(8):2661-8.

59.Shen C, Lancaster CS, Shi B, Guo H, Thimmaiah P, Bjornsti MA. TOR signaling is a determinant of cell survival in response to DNA damage. Mol Cell Biol. 2007;27(20):7007-17.

60.Yurov YB, Vorsanova SG, Iourov IY. The DNA replication stress hypothesis of Alzheimer's disease. ScientificWorldJournal. 2011;11:2602-12.

61. Bester AC, Roniger M, Oren YS, et al. Nucleotide deficiency promotes genomic instability in early stages of cancer development. Cell. 2011;145(3):435-46.

62. Burhans WC, Weinberger M. DNA replication stress, genome instability and aging. Nucleic Acids Res. 2007;35(22):7545-56.

63. Buisson R, Boisvert JL, Benes CH, Zou L. Distinct but Concerted Roles of ATR, DNA-PK, and Chk1 in Countering Replication Stress during S Phase. Mol Cell. 2015;59(6):1011-24.

64.Chen J, Cohen ML, Lerner AJ, Yang Y, Herrup K. DNA damage and cell cycle events implicate cerebellar dentate nucleus neurons as targets of Alzheimer's disease. Mol Neurodegener. 2010;5:60.

65.Liu S, Opiyo SO, Manthey K, et al. Distinct roles for DNA-PK, ATM and ATR in RPA phosphorylation and checkpoint activation in response to replication stress. Nucleic Acids Res. 2012;40(21):10780-94.

66. Pandita TK. The role of ATM in telomere structure and function. Radiat Res. 2001;156(5 Pt 2):642-7.

67. Shackelford DA, Tobaru T, Zhang S, Zivin JA. Changes in expression of the DNA repair protein complex DNA-dependent protein kinase after ischemia and reperfusion. J Neurosci. 1999;19(12):4727-38.

68. Shackelford DA. DNA end joining activity is reduced in Alzheimer's disease. Neurobiol Aging. 2006;27(4):596-605.

69. Davydov V, Hansen LA, Shackelford DA. Is DNA repair compromised in Alzheimer's disease?. Neurobiol Aging. 2003;24(7):953-68.

70. Cardinale A, Racaniello M, Saladini S, et al. Sublethal doses of $\beta$-amyloid peptide abrogate DNA-dependent protein kinase activity. J Biol Chem. 2012;287(4):2618-31.

71.Grune T, Reinheckel T, Davies KJ. Degradation of oxidized proteins in mammalian cells. FASEB J. 1997;11(7):526-34.

72. Nyström T. Role of oxidative carbonylation in protein quality control and senescence. EMBO J. 2005;24(7):1311-7.

73. Kanungo J. DNA-dependent protein kinase and DNA repair: relevance to Alzheimer's disease. Alzheimers Res Ther. 2013;5(2):13. 
74. Simpson JE, Ince PG, Haynes LJ, et al. Population variation in oxidative stress and astrocyte DNA damage in relation to Alzheimertype pathology in the ageing brain. Neuropathol Appl Neurobiol. 2010;36(1):25-40.

75. Le romancer M, Reyl-desmars F, Cherifi Y, et al. The $86-\mathrm{kDa}$ subunit of autoantigen $\mathrm{Ku}$ is a somatostatin receptor regulating protein phosphatase-2A activity. J Biol Chem. 1994;269(26):17464-8.

76. Pucci S, Bonanno E, Pichiorri F, Mazzarelli P, Spagnoli LG. The expression and the nuclear activity of the caretaker gene ku86 are modulated by somatostatin. Eur J Histochem. 2004;48(2):103-10.

77. Gillies G. Somatostatin: the neuroendocrine story. Trends Pharmacol Sci. 1997;18(3):87-95.

78. Johansson 0 , Hökfelt T, Elde RP. Immunohistochemical distribution of somatostatin-like immunoreactivity in the central nervous system of the adult rat. Neuroscience. 1984;13(2):265-339.
79.Chi LM, Wang X, Nan GX. In silico analyses for molecular genetic mechanism and candidate genes in patients with Alzheimer's disease. Acta Neurol Belg. 2016.

80.Burgos-Ramos E, Hervas-Aguilar A, Aguado-Llera D, Puebla-Jimenez L, Hernandez-Pinto AM, Barrios V et al. Somatostatin and Alzheimer's disease. Mol Cell Endocrinol. 2008; 286:104-11.

81.Beal MF, Mazurek MF, Tran VT, Chattha G, Bird ED, Martin JB. Reduced numbers of somatostatin receptors in the cerebral cortex in Alzheimer's disease. Science. 1985;229(4710):289-91.

82.Saiz-sanchez D, Ubeda-bañon I, De la rosa-prieto C, et al. Somatostatin, tau, and beta-amyloid within the anterior olfactory nucleus in Alzheimer disease. Exp Neurol. 2010;223(2):347-50.

83. Mimori T, Hardin JA, Steitz JA. Characterization of the DNA-binding protein antigen $\mathrm{Ku}$ recognized by autoantibodies from patients with rheumatic disorders. J Biol Chem. 1986;261(5):2274-8. 